\title{
Fatigue Life Prediction of Magnetorheological Elastomers Subjected to Dynamic Equi-Biaxial Cyclic Loading
}

Tony Betts

Technological University Dublin, anthony.betts@tudublin.ie

Yanfen Zhou

Technological University Dublin, yanfen.zhou@mydit.ie

Stephen Jerrams

Technological University Dublin, stephen.jerrams@tudublin.ie

See next page for additional authors

Follow this and additional works at: https://arrow.tudublin.ie/scschcpsart

\section{Recommended Citation}

Betts, A. et al. (2014). Fatigue Life Prediction of Magnetorheological Elastomers Subjected to Dynamic Equi-Biaxial Cyclic Loading. Materials Chemistry and Physics, vol. 146 , pp.487-492. doi.org/10.1016/ j.matchemphys.2014.03.059

This Article is brought to you for free and open access by the School of Chemical and Pharmaceutical Sciences at ARROW@TU Dublin. It has been accepted for inclusion in Articles by an authorized administrator of ARROW@TU

Dublin. For more information, please contact

arrow.admin@tudublin.ie, aisling.coyne@tudublin.ie, gerard.connolly@tudublin.ie.

Funder: IRCSET

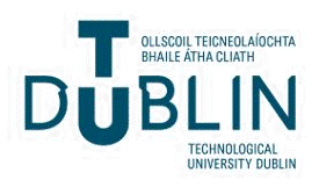




\section{Authors}

Tony Betts, Yanfen Zhou, Stephen Jerrams, and Lin Chen

This article is available at ARROW@TU Dublin: https://arrow.tudublin.ie/scschcpsart/39 
Dublin Institute of Technology

ARROW@DIT

Articles

Centre for Elastomer Research

2014

Fatigue life prediction of magnetorheological elastomers subjected to dynamic equi-biaxial cyclic loadin

Yanfen Zhou

Stephen Jerrams

Anthony Betts

Beijing Aeronautical Science and Technology Research Institute, Commercial Aircraft Corporation of China, PR China

Follow this and additional works at: http://arrow.dit.ie/cerart

Part of the Polymer and Organic Materials Commons

This Article is brought to you for free and open access by the Centre for Elastomer Research at ARROW@DIT. It has been accepted for inclusion in Articles by an authorized administrator of ARROW@DIT. For more

information, please contact yvonne.desmond@dit.ie, arrow.admin@dit.ie. 


\title{
Fatigue life prediction of magnetorheological elastomers subjected to dynamic equi- biaxial cyclic loading
}

\author{
Yanfen Zhou ${ }^{\text {a }}$, Stephen Jerrams ${ }^{a}$, Anthony Betts ${ }^{b}$, Lin Chen ${ }^{c}$ \\ ${ }^{a}$ Centre for Elastomer Research, Focas Research Institute, Dublin Institute of Technology, Dublin 8, \\ Ireland \\ ${ }^{\mathrm{b}}$ Applied Electrochemistry Group, Focas Research Institute, Dublin Institute of Technology, \\ Dublin 8, Ireland \\ ${ }^{\mathrm{c}}$ Beijing Aeronautical Science and Technology Research Institute, Commercial Aircraft \\ Corporation of China, PR China
}

\begin{abstract}
Prediction of fatigue life is of great significance in ensuring that dynamically loaded rubber components exhibit safety and reliability in service. In this text, the dynamic equi-biaxial fatigue behaviour of magnetorheological elastomer (MREs) using a bubble inflation method is described. Wöhler (S-N) curves for both isotropic and anisotropic MREs were produced by subjecting the compounds to cycling over a range of stress amplitudes $\left(\sigma_{\mathrm{a}}\right)$ between $0.75 \mathrm{MPa}$ and 1.4 MPa. Changes in physical properties, including variation in stress-strain relations and complex modulus $\left(\mathrm{E}^{*}\right)$ during the fatigue process were analysed. It was found that the complex modulus of MRE samples decreased throughout the entire fatigue test and failure took place at a limiting value of approximately 1.228 $\mathrm{MPa} \pm 4.38 \%$ for isotropic MREs and $1.295 \pm 10.33 \%$ for anisotropic MREs. It was also determined that a dynamic stored energy criterion can be used as a plausible predictor in determining the fatigue life of MREs.
\end{abstract}

Keywords: magnetic materials; fatigue; mechanical properties; hysteresis

\footnotetext{
*Corresponding author, email: yanfen.zhou@ mydit.ie, phone: 00353867238576
} 


\section{Introduction}

Magnetorheological (MR) materials belong to a category of smart materials whose rheological properties can be controlled rapidly and reversibly by the application of an external magnetic field [1]. A magnetorheological elastomer (MRE) is a composite material that comprises an elastomeric matrix and magnetic particles. The matrix of MREs can be soft materials, such as silicone rubber [2, 3], relatively harder materials, such as natural rubber [4], or elastomers with easily adjustable properties, such as polyurethane [5, 6]. Carbonyl iron is the most widely used magnetic particle because of its excellent soft magnetic property and spheroidal shape [7]. In the presence of an external magnetic field, the magnetic particles can align into chains parallel to the direction of the applied field [8]. These aligned composites display strong anisotropy in their mechanical, electrical, magnetic and thermal properties.

The magnetorheological effect, is defined as the change in performance of an MRE under an external magnetic field and is a significant property in respect of the functionality of the composite. Currently, most research into MREs has been concerned with the MR effect which is usually characterised by shear modulus $[9,10]$, stiffness [11] and damping capability [12]. The mechanical properties of MREs, including modulus and damping capability, have a very large bearing on whether components manufactured from them will find wide practical applications. The performance of an MRE can be influenced by the composition and microstructure of the composite [9], the external magnetic field [3] and the test conditions [13].

One of the most important physical characteristics needed from modern materials is fatigue strength and for MREs this property has been under-researched. Moreover, the 
complex loading and high deformations in service of most rubber components necessitates multi-axial testing methods. To this end, the primary aim of the research described here was to investigate the equi-biaxial fatigue behaviour of MREs under cyclic loading. The specific objectives were: to establish Wöhler $(\mathrm{S}-\mathrm{N})$ curves for isotropic and anisotropic MREs subjected to equi-biaxial dynamic loading; to study the stress-strain behaviour and changes in complex modulus during the fatigue process and to provide a plausible and reliable predictor for determining the fatigue life of MREs subjected to equi-biaxial cyclic loading.

\section{Materials and methods}

\subsection{Materials}

A room temperature vulcanized (RTV) silicone rubber comprising the base elastomer and a catalyst, procured from Axson Technology, UK, was used as the matrix material. This material was chosen because the modulus of silicone allows mobility of the ferromagnetic particles so that an MRE can be easily processed. This in turn leads to an improved magnetorheological effect. Soft carbonyl iron $(\mathrm{CS}$ grade, d50 = $6.0-7.0 \mu \mathrm{m}$, density $=7.86 \mathrm{~g} / \mathrm{cm}^{3}$, supplied by BASF, Germany) was selected as the magnetic particle because it possesses excellent soft magnetic properties and high saturation magnetization.

\subsection{Fabrication of MREs}

Both isotropic and anisotropic MREs with a carbonyl iron content of $20 \mathrm{vol} \%$ and a thickness of $1 \mathrm{~mm}$ were produced. Firstly, silicone rubber was mixed with the catalyst at a 10:1 ratio. Then the carbonyl iron particles were incorporated into the mixture and mechanically stirred to distribute the particles evenly in the elastomer matrix. The whole mixture was degassed in a vacuum to remove entrapped air bubbles and then poured into a 
mould. After further degassing in the mould, the compound was kept at room temperature for 48 hours to allow solidification. For anisotropic MREs, the compound was cured in the presence of a magnetic field using a Halbach Array after degassing had taken place. The Halbach array provided a mean magnetic flux density of $400 \mathrm{mT} \pm 5 \%$ over the $50 \mathrm{~mm}$ nominal diameters of the test samples.

\subsection{Microscopy observation}

The microstructures of the isotropic and anisotropic MREs were observed using a Scanning Electron Microscope (SEM, Zeiss Supra). Samples were coated with a fine layer of gold to make them conductive prior to observation. All images were taken with an accelerating voltage of $5 \mathrm{KV}$ using an SE (Secondary Electron) detector.

\subsection{Equi-biaxial fatigue testing}

Fig.1 depicts the bubble inflation system used to determine equi-biaxial fatigue behaviour of MREs. This system eliminates the disadvantages exhibited by stretch frames due to stress concentration in the clamping region, friction, inertia and the limited stretch ratios that can be achieved [14]. The system comprises controlled deformation cycles using a hydraulic inflation medium with a vision system and simultaneous data recording. The theory for obtaining stress-strain relations at the bubble pole which underpins the testing system is described elsewhere [15]. The engineering stress $\left(\sigma_{\text {Eng }}\right)$ and the principal stretch ratio can be obtained using the following equations [16]:

$$
\begin{gathered}
\sigma_{E n g}=P\left(r / 2 t_{0}\right) \cdot \lambda \\
\lambda=\left(\left(X_{\text {cir }}-X_{\text {orig }}\right) / X_{\text {orig }}\right)+1
\end{gathered}
$$


Where, $P(\mathrm{MPa})$ is the applied pressure to inflate a thin sheet, $r(\mathrm{~mm})$ the radius of the curvature, $t_{0}(\mathrm{~mm})$ the unstrained specimen thickness, $X_{c i r}$ is the circumferential point spacing at the bubble pole and $X_{\text {orig }}$ is the original point spacing.

Following the preparation of $50 \mathrm{~mm}$ disc test samples, they were constrained in the bubble inflation system's inflation orifice. Initially, quasi-static tests were carried out to provide a value of failure stress and stress-strain relationship for first loading. This allowed the equi-biaxial dynamic test parameters to be set. Thereafter, fatigue tests were conducted over a range of stress amplitudes with a minimum stress of zero, under engineering stress control. Pressure was applied hydraulically to the samples causing them to inflate. The vision system, utilising two charge coupled device (CCD) cameras, recorded the movement of the centre of specific points on a circumferential line passing through the pole on the surface of a sample during inflation and deflation. Stress values were simultaneously calculated from the applied pressure and bubble geometry, while strain values were calculated from the change in circumferential distance between specific points, using three dimensional position coordinates obtained from the vision system output. Throughout these tests, the dynamic test facility continually records dimensional changes in the bubble and corrects pressure limits to maintain constant engineering stress amplitudes. Concurrently, accumulated cycles are counted. Samples were not cycled in the presence of a magnetic field in the tests described here.

\section{Results and Discussion}

\subsection{Microstructure of isotropic and anisotropic MREs}

The SEM images for isotropic and anisotropic MREs are shown in Fig.2. It can be observed that carbonyl iron particles were distributed randomly in the isotropic MREs. In 
contrast, they formed chain-like structures in the direction of the magnetic field in anisotropic MREs.

\subsection{S-N curves}

Quasi-static tests showed that the average strength at failure was 3.5 MPa for isotropic MREs and 4.1 MPa for anisotropic MREs. Equi-biaxial fatigue tests were then carried out at four different stress amplitudes ranging between $0.75 \mathrm{MPa}$ and $1.4 \mathrm{MPa}$ with a minimum stress of zero under engineering stress control. A minimum of three tests were carried out for each stress amplitude and subsequently standard S-N curves were produced to give fatigue life predictions for isotropic and anisotropic MREs, as shown in Fig. 3.

When fatigue lives were compared at the same stress amplitudes, it was found that anisotropic MREs exhibit greater fatigue resistance than isotropic MREs. This is unquestionably due to the formation of carbonyl iron chains in anisotropic MRE samples during the curing process and the stronger magnetic interactions between the aligned particles.

\subsection{Stress-strain behaviour}

Elastomers exhibit a characteristic ' $\mathrm{S}$ ' shaped stress-strain curve in both loading and unloading cycles. Hysteresis is present in the loading and unloading curves due to the continual breaking and re-formation of the weak van der Waals bonds between the chains as they move relative to each other [17]. The presence of filler increases the stiffness and durability of elastomer but at the same time increases stress softening (the Mullins effect) [18] which results from the breakdown of the filler structure. This phenomenon comprises both the interaction between the surfaces of filler particles and the rubber as well as the breakdown of filler aggregates. When subjected to a large number of cycles, stress 
softening and hysteresis in filled rubbers are significant. The stress-strain behaviour of isotropic and anisotropic MREs at a stress amplitude of $0.75 \mathrm{MPa}$ is depicted in Fig.4 and Fig.5 respectively. The plots clearly indicate that the algorithm employed to maintain constant engineering stress limits, as the bubble material softened, kept the stress range within acceptable levels. It can be observed that stress softening and hysteresis continued as cycles accumulated and was particularly pronounced in the first hundred cycles for both isotropic and anisotropic MREs. Furthermore, the dynamic cyclic loading induced an increase in permanent set as each test progressed, but this increase was much greater in isotropic MREs than in anisotropic MREs, as shown in Fig. 6. This indicates that the stiffer anisotropic MREs exhibit lower extensibility.

\subsection{Complex modulus}

It is usual for the modulus of a filled rubber to decrease significantly in the first few cycles of a physical test as a result of the Mullins effect [19]. Previous research into fatigue of non strain-crystallising elastomers (ethylene propylene diene monomer, EPDM and styrene-butadiene rubber, SBR) by Abraham [20, 21] and Alshuth et al [22] suggested that when subjected to uniaxial loading these materials exhibited a limiting value of complex tensile modulus $\left(\mathrm{E}^{*}\right)$ and this value could be used effectively to design against fatigue failure in rubber components. The concept of using a limiting value of $\mathrm{E}^{*}$ was further supported by the research of Jerrams et al [23, 24] and Hanley et al [25, 26] for EPDM samples, both swollen and unswollen, subjected to equi-biaxial stress cycles.

The complex modulus for isotropic and anisotropic MREs was approximated from the stress-strain curves, as depicted in Fig.7 and Fig. 8. It was found that the complex modulus decreased throughout the entire fatigue process for each stress amplitude and attained a 
limiting value at failure. For isotropic MREs, fatigue failure took place at $\mathrm{E}^{*}$ values between 1.16 MPa and 1.29 MPa (1.228 MPa $\pm 4.38 \%)$ while for anisotropic MREs, failure occurred at $\mathrm{E}^{*}$ values between 1.16 MPa and 1.41 MPa (1.295 MPa $\left.\pm 10.33 \%\right)$. The results described here further strengthen the conclusion that fatigue failure occurs (within limits) at a material specific value of $\mathrm{E}^{*}$ irrespective of the loading level.

\subsection{Dynamic stored energy}

Dynamic stored energy (per unit volume), which is defined as the strain energy available in the unloading cycle, can also be determined from stress-strain curves [27]. Dynamic stored energy is given by the area below the unloading curve and it represents the elastic stored energy in the rubber sample.

The dynamic stored energy in cycles for tests on isotropic and anisotropic MREs was calculated and this parameter is shown in Fig. 9 and Fig.10 respectively. It can be noted that at a constant stress amplitude, the dynamic stored energy increases with the accumulation of cycles for both isotropic and anisotropic MREs. When plotted against $\log _{10}$ cycles to failure, the dynamic stored energy at failure was found to decrease linearly, indicating that, as suggested by Abraham [19] and others [22, 24], dynamic stored energy can be used as a plausible predictor of fatigue lives for isotropic and anisotropic MREs irrespective of the stress amplitudes applied.

However, it should be noted that the dynamic stored energy in isotropic MREs is higher than that of anisotropic MREs at the same loading conditions. This is illustrated in Fig. 11, where the linear plots of dynamic stored energy at failure versus cycles to failure were presented together for the isotropic and anisotropic MREs. This difference can be ascribed 
to lower extensibility due to the formation of columnar magnetic particles chains in anisotropic MREs for a given applied stress.

\subsection{Fracture surface}

The fracture surface morphologies of isotropic and anisotropic MREs failed under a range of loading conditions were observed by using SEM and the results are shown in Fig. 12 and Fig.13 respectively. It can be seen from Fig.12 that the cyclic loading induced debonding of the particles from the silicone matrix, leading to the formation of voids and cavitations that finally led to failure of the isotropic samples. Other particles and their agglomerates remained in the fracture surface. Their interfaces with the silicone matrix are very distinct, which indicates the poor interaction between each material. The fracture surface of anisotropic MRE samples was to some extent different to that of isotropic ones as can be noted from Fig.13. Dynamic loading also induced a certain number of particles to debond from the matrices, but there were fewer by comparison with isotropic samples under the same loading conditions. The remaining particles were well embedded in the silicone matrices with superior interfacial characteristics. This supports the conclusion that the fatigue resistance of anisotropic MREs is greater than that of isotropic ones for the same loading levels.

\section{Conclusions}

Bubble inflation provides a critical research method in determining the equi-biaxial fatigue behaviour of MREs. This paper presents the first Wöhler curves for isotropic and anisotropic MREs subjected to equi-biaxial cyclic loading and as such offers a practical approach for determining fatigue life in adaptive elastomeric materials. It has been shown that the fatigue resistance of anisotropic MREs is higher than that of isotropic MREs due to 
the presence of columnar magnetic particle chains formed during the curing process. In the equi-biaxial fatigue tests on MREs, the complex modulus $E^{*}$ decreased throughout the entire test and attained a limiting value of approximately $1.228 \mathrm{MPa} \pm 4.38 \%$ for isotropic MREs and 1.295 MPa $\pm 10.33 \%$ for anisotropic MREs. This value was independent of the stress amplitudes applied and can provide an indicator in respect of preventative maintenance which will allow MRE based rubber components to be replaced prior to costly failure. The dynamic stored energy criterion can be used as a predictor in determining the fatigue life of MREs irrespective of the loading level and the directionality of the ferromagnetic particles.

Future work will focus on dynamic equi-biaxial fatigue tests on isotropic and anisotropic MREs in the presence of an external magnetic field. Equations for dynamic stored energy will be derived for both isotropic and anisotropic MREs to provide an effective energy based fatigue life predictor.

\section{Acknowledgements}

This work was made possible by funding from the Irish Research Council (This funding was initially provided under the auspices of the Irish Research Council for Science, Engineering and Technology, IRCSET).

\section{References}

[1] Anna Boczkowska and Stefan Awietjan. Microstructure and Properties of Magnetorheological Elastomers, a chapter in the book 'Advanced Elastomers, Technology, Properties and Applications', (Ed. A Boczkowska) ISBN 978-953-51-0739-2, Intech, (2012) 382-386

[2] P. R. von Lockette, S. E. Lofland, J. H. Koo, J. Kadlowec, M. Dermond. Dynamic characterization of bimodal particle mixtures in silicone rubber magnetorheological materials, Polymer Testing, 27 (2008) 931-935 
[3] M. Kallio, T. Lindroos, S. Aalto, E. Jarvinen, T. Karna, T. Meinander. Dynamic compression testing of a tunable spring element consisting of a magnetorheological elastomer, Smart Materials and Structures, 16 (2007) 506-514

[4] A. Alberdi-Muniain, N. Gil-Negrete, L. Kari. Influence of carbon black and plasticisers on dynamic properties of isotropic magnetosensitive natural rubber, PLASTICS RUBBER AND COMPOSITES, 41 (2012) 310-317

[5] J. K. Wu, X. L. Gong, L. Chen, H. S. Xia, Z.G. Hu. Preparation and characterization of isotropic polyurethane magnetorheological elastomer through in situ polymerization, Journal of Applied Polymer Science, 114 (2009) 901-910

[6] A. Boczkowska, S. F. Awietjan. Smart composites of urethane elastomers with carbonyl iron, Journal of Materials Science, 44 (2009) 4104-4111

[7] X.S. Lu, M. Li, K.Yang, H.E. Xie, Q. Yin, D. Wang. SEBS Based Magnetorheological Elastomer: Preparation and Property, 7th OAPS Working Paper Series, 2011

[8] A. Boczkowska, S. F. Awietjan. Intelligent magnetorheological elastomer composites, Polymer, 58 (2013) 443-449

[9] S. A. Demchuk, V. A. Kuźmin. Viscoelastic Properties of Magnetorheological Elastomers in the Regime of Dynamic Deformation, Journal of Engineering Physics and Thermophysics, 75 (2002) 396-400

[10] M.Lokander, T. Reitberger, B. Stenberg. Oxidation of natural rubber-based magnetorheological elastomers, Polymer Degradation and Stability 86 (2004) 467-471

[11] A. Boczkowska, S. F. Awietjan and R. Wroblewski. Microstructure-property relationships of urethane magnetorheological elastomers, Smart Materials and Structures, 16 (2007) 1924-1930

[12] C. Bellan, G. Bossis. Field dependence of viscoelastic properties of MR elastomers, Internal Journal of Modern Physics B, 16 (2002) 2447-2453

[13] G.Y. Zhou, J. R. Li. Dynamic behavior of a magnetorheological elastomer under uniaxial deformation: I. Experiment, Smart Mater. Struct. 12 (2003) 859-872

[14] D. J. Charlton, J. Yang. A review of methods to characterize rubber elastic behavior for use in finite element analysis, Rubber Chemistry and Technology, 67 (1994) 481-503

[15] S. Jerrams, N. Murphy, J. Hanley. The significance of equi-biaxial bubble inflation in determining elastomeric fatigue properties, Published in the book 'Advanced Elastomers, Technology, Properties and Applications', (Ed. A Boczkowska) ISBN 978-953-51-0739-2, InTech (2012) p 381

[16] N. Murphy. Providing stress controlled equi-biaxial fatigue test data for elastomers using the bubble inflation method, PhD thesis, Dublin Institute of Technology, 2010

[17] J. T. Bauman. Fatigue, Stress, and Strain of Rubber Components, Hanser Publisher, Munich, (2008) pp 34

[18] L. Mullins. Softening of rubber by deformation, Rubber Chemistry and Technology, 42 (1969), 339-362

[19] F. Abraham, T. Alshuth, S. Jerrams. The effect of minimum stress and stress amplitude on the fatigue life of non strain crystallising elastomers, Journal of Materials and Design, 26 (2005) 239-245

[20] F. Abraham, T. Alshuth, S. Jerrams. Parameter dependence of the fatigue life of elastomers, a chapter in the book Elastomers and Components: Service Life Prediction Progress and Challenges, ISBN 184569100 8, (Published by Woodhead), (2006) 
[21] F. Abraham, T. Alshuth, S. Jerrams. Dependence on mean stress and stress amplitude of fatigue life of EPDM elastomers, Institute of Materials, 30 (2001) 421-425

[22] T. Alshuth, F. Abraham, S. Jerrams. Parameter dependence and prediction of fatigue properties of elastomer products, Rubber Chemistry and Technology, 75 (2002) 635-642

[23] S. Jerrams, N. Murphy, J. Hanley. The significance of equi-biaxial bubble inflation in determining elastomeric fatigue properties, a chapter in the book 'Advanced Elastomers, Technology, Properties and Applications’, (Ed. A Boczkowska) ISBN 978-953-51-0739-2, Intech, (2012), pp 382-386

[24] S. Jerrams, J. Hanley, N. Murphy, H. Ali. Equi-biaxial fatigue of elastomers -The effect of oil swelling in specimen fatigue life, Rubber Chemistry and Technology, 81 (2008) $638-649$

[25] J. Hanley, S. Jerrams, N. Murphy. The effect of oil swelling on the fatigue life of EPDM samples subjected to equi-biaxial cyclic loading. Time Dependent Behaviour of Rubber Conference, the Rubber in Engineering Group of the Institute of Materials, Minerals and Mining, London, (2008)

[26] J. Hanley. PhD Dissertation. Swelling effects in dynamic equi-biaxial testing of EPDM elastomers by the bubble inflation method, Dublin Institute of Technology (DIT), (2008)

[27] D. Roylance, "Stress-Strain Curves", MIT Press, Cambridge, MA (2001) 